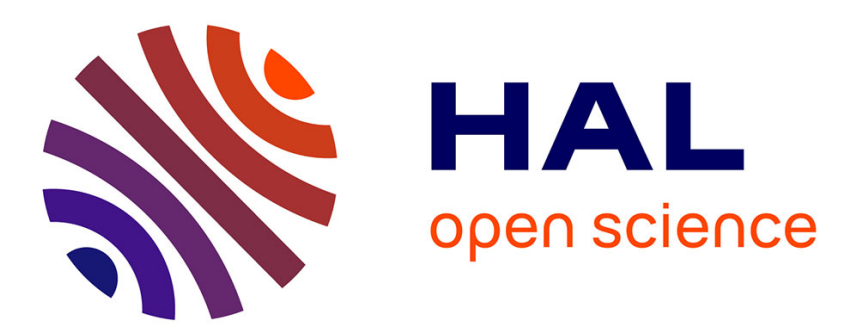

\title{
Influence of Secondary Phase Particles on Zr-Alloy Plastic Flow Stability and Fracture
}

\author{
S. Nikulin, M. Shtremel, V. Markelov
}

\section{To cite this version:}

S. Nikulin, M. Shtremel, V. Markelov. Influence of Secondary Phase Particles on Zr-Alloy Plastic Flow Stability and Fracture. Journal de Physique IV Proceedings, 1996, 06 (C6), pp.C6-133-C6-143. 10.1051/jp4:1996613 . jpa-00254441

\section{HAL Id: jpa-00254441 https://hal.science/jpa-00254441}

Submitted on 1 Jan 1996

HAL is a multi-disciplinary open access archive for the deposit and dissemination of scientific research documents, whether they are published or not. The documents may come from teaching and research institutions in France or abroad, or from public or private research centers.
L'archive ouverte pluridisciplinaire HAL, est destinée au dépôt et à la diffusion de documents scientifiques de niveau recherche, publiés ou non, émanant des établissements d'enseignement et de recherche français ou étrangers, des laboratoires publics ou privés. 


\title{
Influence of Secondary Phase Particles on Zr-Alloy Plastic Flow Stability and Fracture
}

\author{
S.A. Nikulin, M.A. Shtremel and V.A. Markelov* \\ Moscow State Institute of Steel and Alloys, Leninsky av., 4, 117936, Moscow, Russia \\ * A.A. Bochvar, All-Russia Research Institute of Inorganic Materials, P.O. Box 369, 123060 Moscow, \\ Russia
}

\begin{abstract}
The influence of intermetallic particles and hydrides on the total and local ductility as well as on the fracture mechanism in $\mathrm{Zr}-2.5 \mathrm{Nb}$ and $\mathrm{Zr}-1 \mathrm{Nb}-1.3 \mathrm{Sn}-0.4 \mathrm{Fe}$ alloys was studied by the methods of acoustic emission (AE). Based on measurements of maximum (peak) values of $A E$ amplitudes depending on secondary phase size and distribution two alternative mechanisms were established of loss of flow stability in alloys under tension: geometrical loss of strength for uniform fine particle distribution, and microcracking at the stage of uniform strain for coarse particle aggregates or fine particle stringers. Ways of increasing the fracture toughness resistance of alloys were suggested by increasing the stability of local flow at a crack tip through optimization of matrix deformation ability, secondary phase size and distribution within matrix. Analysis is given to quantitative relationships between fracture toughness and microstructure characteristics of alloys. Original devices and techniques were developed to quantitatively analyze local processes of strain and fracture based on $\mathrm{AE}$ measurements which allows assessment of unstable flow zones and measurement of microcrack $5 \mu \mathrm{m}$ and more in size.
\end{abstract}

\section{INTRODUCTION}

Ductility of alloys in the process of working and their tough fracture resistance depend in the end upon their ability for stable plastic flow under the action of tensile stresses without strain being localized. The earlier loss of plastic flow stability at the macrolevel, e.g., upon rolling or area reduction can be a cause of a lower technological ductility [1] and at the microlevel it can degrade the fracture resistance [2].

The instability may vary in a wide range, namely, from a neck initiation under tension to appearance of slip bands and individual dislocation aggregates in a much strained-fragmented structure. The reasons of instability are also different: they may be mechanical - a loss of the carrying capacity due to insufficient strengthening in a weak section or may be related to the specific features of structure.

In practice the moment of the flow stability loss is not always specified by the strain diagram and commences much earlier than it should have occurred at "geometrical" loss of strength by the mechanism different from the traditional one.

However, due to a lack of experimental data the possibility of an earlier flow stability loss on structure defects or the secondary phase and conditions under which this mechanism is realized remained unknown for a long period of time.

The direct experimental evidence of the existence of such a mechanism has been obtained by the authors from studying the deformation of two-phase high manganese steels [4]. 
To pinpoint the routes of improving technological ductility and fracture resistance one needs to formulate and rank the structural means of governing the plastic flow stability and fracture. The method of assessing the margin of ductility and toughness of alloys must be simple to operate and interpret the results. In this work the analysis of this kind has been carried out using $\mathrm{Zr}$-alloys-structural materials of responsible components of nuclear reactors. Use was made of a complex approach based on a joint analysis of strain diagrams, acoustic emission and uniaxial tension fractures.

For the analysis of deformation processes the loading schema is most suitable that is used in uniaxial tension tests since it is the most rigid one among those providing the plastic strain uniformity.

It is known, that for the material flow to be stable in the process of deformation under the action of true stress $\sigma$ and strain $\varepsilon$, the intensity of hardening must be $(\mathrm{d} \sigma / \mathrm{d} \varepsilon)>\sigma[1]$. Instability of the flow accompanied by necking will set in at $(\mathrm{d} \sigma / \mathrm{d} \varepsilon)=\sigma$ which usually occurs without disturbing the material continuity by the "geometrical loss of strength" - fluctuations in specimen diameter (section) at strain $\varepsilon=\varepsilon_{\mathrm{u}}[1]$.

For analysis of the tensile stress-strain curves it is possible to approximate them in the true coordinates by equation

$$
\sigma=\mathrm{k} \times \varepsilon^{\mathrm{n}}
$$

[3], where $n$ is the coefficient of strain hardening. Equation (1) predicts the loss of the flow stability when strain $\varepsilon_{\mathfrak{u}}=n$ is reached. Hence, the maximum uniform strain $\varepsilon_{\mathfrak{u}}^{\max }$ is determined by the intensity of strain hardening $n$, and the nominal stress under the maximum load (ultimate tensile strength)

$$
\sigma_{u}=k(n / e)^{n}
$$

where $\mathrm{e}=2.718$. At the microlevel the coefficient of hardening $n$ determines the kinetics of pore growth and coalescence upon tough fracture and, hence, the energy intensity of the fracture process [2].

In reality the strain $\varepsilon_{\mathrm{u}}=\mathrm{n}$ is often not reached since the moment the flow stability is lost is not always specified by the strain diagram; of importance are also differences in the kinetics and mechanism of fracture that were early studied using martensitic - austenitic steels [4-5] and Zr-alloys [7-9].

\section{EXPERIMENTAL PROCEDURE}

\subsection{Material}

To study the mechanisms of flow stability loss and tough fracture under tension and to find out a general approach to governing ductility and fracture resistance alloys were taken that have different compositions and structures of matrix phases as well as different types, sizes and distributions of secondary phases.

The first one was $\mathrm{Zr}-2.5 \mathrm{Nb}$ in which by the anneal within $500-600^{\circ} \mathrm{C}$ after the cold work the $\alpha_{\mathrm{Zr}}$-matrix was produced having grains $3.4-5.6 \mu \mathrm{m}$ in section and $\beta_{\mathrm{Nb}}$-phase $0.02-0.10$ $\mu \mathrm{m}$ in section of the volume fraction $1.5-2.0 \%$ at different recrystallization grades $\mathrm{V}_{\mathrm{r}}=1-75 \%$ with the invariable texture type and constant coefficient of strengthening $n=0.13-0.17$ in the axial direction and $n=0.03-0.08$ in the transverse one [7]. By altering the texture via the alloy quenching from $790-860^{\circ} \mathrm{C}$ from the $(\alpha+\beta)$ region the coefficient of strengthening was varied within $n=0.06-0.14$ for the axial specimens and $n=0.04-0.10$ for the transverse ones; 
the structure consisting of the transformed $\alpha^{\prime} \mathrm{Zr}$-phase and the residual $\beta_{\mathrm{Zr}}$-phase $0.01-0.1 \mu \mathrm{m}$ in size in addition to grains of the primary $\beta_{\mathrm{Zr}}$-phase and $\beta_{\mathrm{Nb}}$ particles. By the recrystallized alloy hydrogenation to $0.01-0.02 \%$ mass $\mathrm{H}_{2} \quad 10-200 \mu \mathrm{m}$ precipitates of brittle $\mathrm{Zr}$ hydrides were induced in the $\alpha_{\mathrm{Zr}}$-matrix [8].

By the $500^{\circ} \mathrm{C}$ hydrogenation of the heat treated specimens followed by cooling at different rates $\left(2\right.$ to $50^{\circ} \mathrm{C} / \mathrm{min}$ ) various size hydrides were obtained of the mean length from $50-100$ $\mu \mathrm{m}$ to $10-20 \mu \mathrm{m}$. For the tests specimens were taken with hydrides uniformly distributed within the gauge length volume. Hydrides of the axial and transverse specimens were similarly oriented primarily along the speciemen axis [8].

The other studied object was a multicomponent alloy $\mathrm{Zr}-1.3 \mathrm{Sn}-1 \mathrm{Nb}-0.4 \mathrm{Fe}$ ( with the $\mathrm{Fe}$ content of $0.20,0.33$ and $0.46 \%$ ) in which the size of intermetallic phase particles within 0.05-1.2 $\mu \mathrm{m}$ and their distribution in the recrystallised $\alpha_{\mathrm{Zr}}$-matrix were changed by working/heat treatment (WHT) at the invariable volume fraction of particles $(3.0-3.5 \% \mathrm{vol})$ and the constant coefficient of strengthening $n=0.08-0.14$ [9]. Use was made of $\mathrm{WHT}_{\mathrm{s}}$ with $\beta$-quenching from $950^{\circ} \mathrm{C}$ prior to multiple cold rollings or without them and final anneal at $590^{\circ} \mathrm{C}[9]$. Various $\mathrm{WHT}_{\mathrm{s}}$ resulted in the fully recrystallized matrix (the grain size of 3.2-5.1 $\mu \mathrm{m}$ ) in the conditions characterized either by the uniform distribution of fine particles (up to $0.3 \mu \mathrm{m}$ in section) or aggregates of coarse particles (up to $1.2 \mu \mathrm{m}$ ) near the grain boundaries or stringers of fine particles within them [9].

\subsection{Tensile Tests}

Uniaxial tensile tests were conducted at room temperature in a screw-driven Instron machine at a strain rate of $4 \times 10^{-4} \mathrm{~s}^{-1}$, using specimens of $3 \mathrm{~mm}$ diameter $(10000 \mathrm{~N}$ scale, the diagram recorded in $30 \mathrm{~N}: 1 \mathrm{~mm}$ and $1 \mathrm{~mm}: 50 \mathrm{~mm}$ scale).

The strain diagrams in the true coordinates $\sigma-\varepsilon$ were approximated with eq. (2) the parameters of which were determined by the least square method (LSM) as coefficient of linear regression equation:

$$
\ln \sigma=\ln k+n \cdot \ln e
$$

The uniform strain diagrams $\sigma(\varepsilon)$ for all the alloys and conditions studied agreed well with eq. (2). The residual dispersion of the regression (3) did not differ from the dispersions of the flow stress at the confidence level not less than 95\% according to Fisher criterion.

\subsection{Acoustic Emission Measurements}

The kinetics of the fracture under tension were observed by measuring the peak amplitudes af AE signals [6] with non-resonant transducers which made it possible to observe the processes of inner crack initiation and evolution in real time. The AE facility is schematically shown in Fig.1. A piesotransducer with a damped piesoelement and a cone acoustic trap [6] was sited at the end of the tensile specimen.

The specially designed and manufactured receiver-amplifier devices processed input signals linearly by a level of $\pm 15 \mathrm{~V}$ in the frequency range of 0.01 to $10 \mathrm{MHz}$ and the dynamic range up to $780 \mathrm{~dB}$ at the rate of the peak detector extraction of extreme signal amplitudes equal to $50 \mu \mathrm{s}$. The level of the apparatus noise brought to the inlet is $10^{-3} \mathrm{~B}$.

The detected signal was recorded and processed in the digital form with a specially designed microprocessor analyzer of signals (MAS) and AE diagrams to determine the $\mathrm{AE}$ parameters were analyzed with IBM PC. 
The programs of diagram processing allowed automated measurement at the acoustic noise level $U_{n}$ in an area where the Kaiser effect applies, and the digitation of the peak amplitudes of acoustic signals relative to the noise level $V_{p}=20 \cdot \lg \left(U_{p} / U_{n}\right)$.

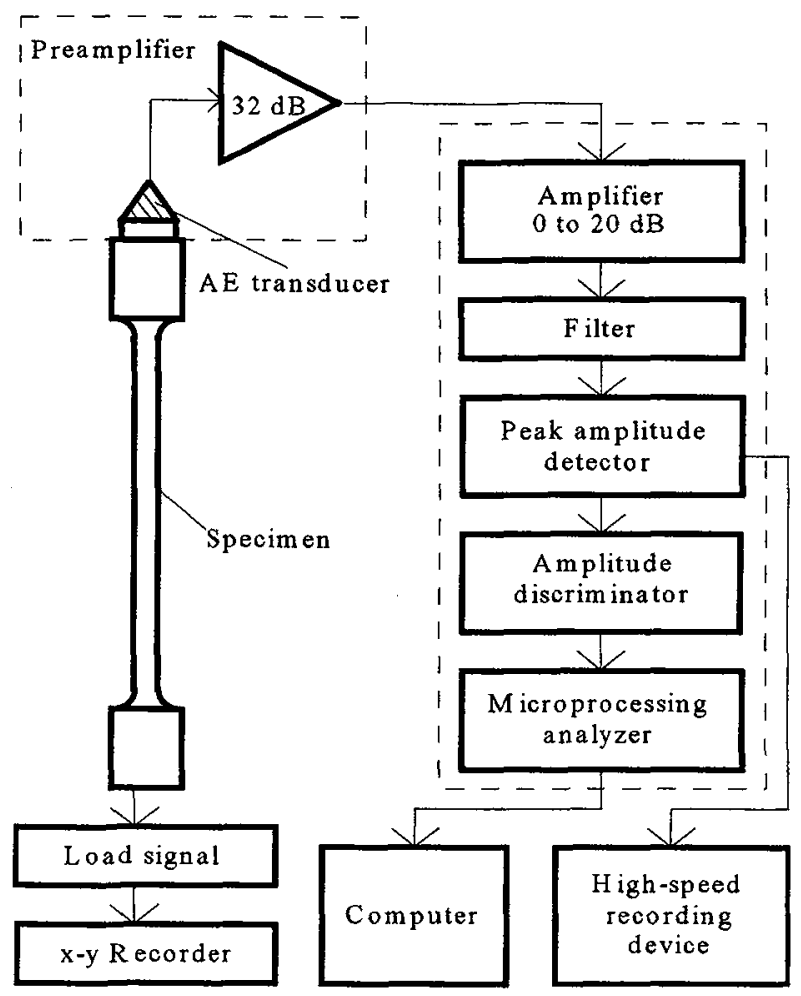

Figure 1: Schematic of acoustic emission facility.

\subsection{Microstructure Analysis and Fractography}

Macro- and microfractographic analyses were carried out in an optical microscope MBS-9 and scanning microscopes Stereoscan-150 and JSM-840 at the magnification of 30 to 3000 as well as in a measuring microscope UIM-21.

\section{RESULTS}

\subsection{Strain Diagrams and Acoustic Emission}

The characteristic strain diagrams and $\mathrm{AE}$ diagrams for $\mathrm{Zr}-2.5 \mathrm{Nb}$ and $\mathrm{Zr}-1.3 \mathrm{Sn}-1 \mathrm{Nb}-$ $0.4 \mathrm{Fe}$ alloys having different structures are illustrated in fig.2-4. With $\mathrm{AE}$ recorded 56 specimens of the above alloys in all structure conditions were tested. Fig.5 shows dependence $\mathrm{e}_{\mathrm{u}}(\mathrm{n})$ for all alloys and conditions.

The uniform deformation $e_{u}$ is basically determined by the matrix recrystallization grade $V_{r}$ [7]: at $V_{r}<25 \% \quad e_{u}<n$ for axial and transverse specimens (fig. 5a). With an increase of $V_{r}$ the uniform deformation grows to reach $\mathrm{e}_{\mathrm{r}}=\mathrm{n}$ at $\mathrm{V}_{\mathrm{r}}=50-74 \%$. In unrecrystallized specimens $\left(\mathrm{V}_{\mathrm{r}}<25 \%\right)$ the flow stability loss takes place due to "internal" necking from microcracks at points where twins encounter slip bands and grain boundaries even at very low strengthening 
$\mathrm{n}<0.15$ [7]. Here before the load starts dropping in axial specimens from 1 to 5 strong AE signals of the amplitude of $20-45 \mathrm{~dB}$ (fig. $2 \mathrm{~b}$ ) are recorded that are effected by the opening of several microcracks observed as pores $0.03-0.09 \mathrm{~mm}$ in section (this was observed in axial sections taken from the neck center that were metallographically analyzed layer-by-layer after recording the signals [7]). In transverse specimens the internal necking due to cracks arising from twinning is possible even at very low strengthening $\mathbf{n}<0.05$.

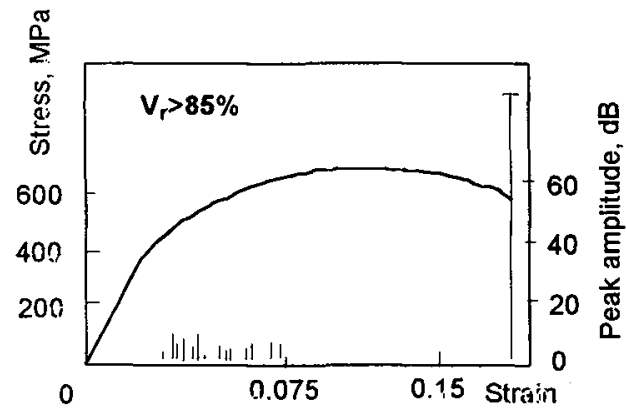

a)

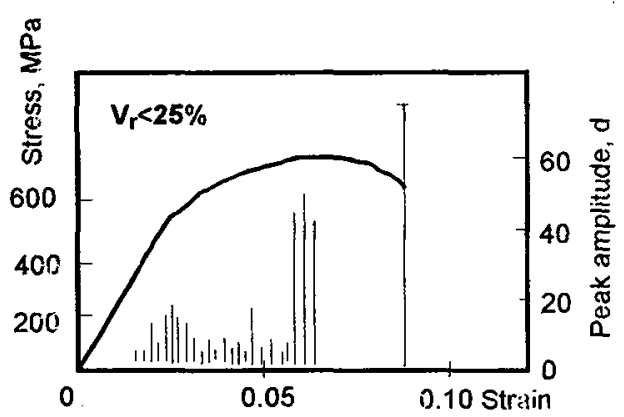

b)

Figure 2: Diagrams of strain and $\mathrm{AE}$ upon tension of $\mathrm{Zr}-2.5 \% \mathrm{Nb}$ hydride free samples.

In essentially fully recrystallized $\mathrm{Zr}-1.3 \mathrm{Sn}-1 \mathrm{Nb}-0.4 \mathrm{Fe}\left(\mathrm{V}_{\mathrm{r}}>85 \%\right)$ the intermetallic particles are available in appreciably higher amounts (3-3.5\% vol.) than in $\mathrm{Zr}-2.5 \mathrm{Nb}$ and their sizes are larger. Upon tension of axial specimens of the alloy in every condition the coefficient of strengthening is $n=0.08-0.16$. For all conditions described by the uniform distribution of fine particles the relation $e_{u}=n$ is fulfilled (fig. 5b). The early loss of the flow stability at $e_{u}<n$ is only observed when coarse particles $0.4-1.2 \mu \mathrm{m}$ in size are available near grain boundaries or there are stringers of fine $(0.05-0.3 \mu \mathrm{m})$ particles (fig. 6). Correspondingly, upon tension of coarse particle aggregates containing specimens to the maximum load from 2 to 10 strong $\mathrm{AE}$ signals of the 15-42 dB amplitude are recorded (fig. $3 b$ ) and after them the strain by $\Delta \varepsilon=1$ $2 \%$ more results in necking. After this series of signals the layer-by-layer metallographic analysis of the axial sections revealed in the nucleated neck (at the concentrated area reduction of 25-30\%) several pores-microcracks $25-100 \mu \mathrm{m}$ in size. Upon the further neck evolution (with a load decrease) only at 1 to $3 \mathrm{~s}$ before the speciemen fracture 5-7 $\mathrm{AE}$ signals are recorded (fig. $3 b$ ) that correspond to the formation of axial cracks-laminations on coarse particle aggregates observed at fracture surfaces.

Brittle hydride incorporation into the recrystallized $\mathrm{Zr}$-matrix of $\mathrm{Zr}-2.5 \mathrm{Nb}$ alloy significantly alters the mechanism and kinetics of tough fracture under tension [8]. Upon tension of all axial specimens and some transverse ones containing fine hydrides $(10-20 \mu \mathrm{m}$ long) the relation $\varepsilon_{\mathrm{u}}=\mathrm{n}$ is fulfilled, namely, the neck under tension results from a "geometrical" loss of strength (fig. 5c). Half of the transverse specimens revealed one or two strong AE signals (up to $37 \mathrm{~dB}$ ) before the maximum load is reached (fig. $4 \mathrm{~b}$ ) and in this case the initiation of necking in them occured earlier at $\varepsilon_{\mathrm{u}}<\mathrm{n}$. The fractures in those specimens have a deep central ellipsoidal tough crack [8]. 


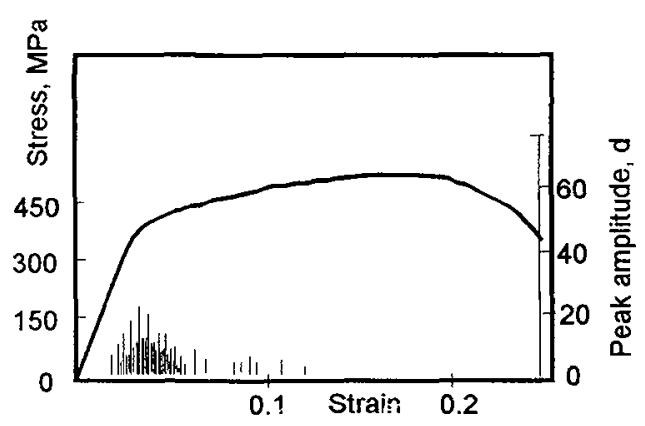

a)

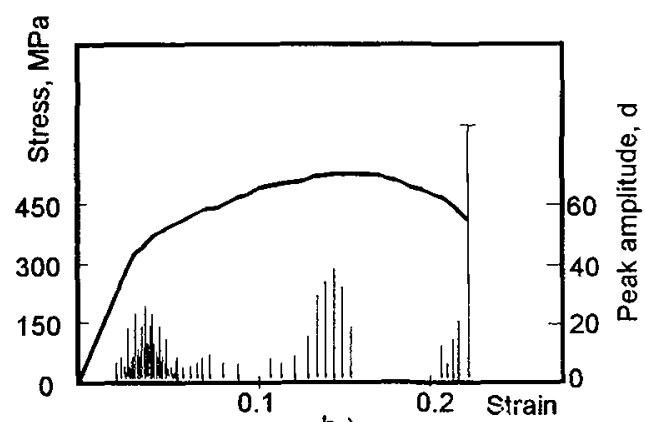

b)

Figure 3: Diagrams of strain and $\mathrm{AE}$ upon tension $\mathrm{Zr}-1.3 \% \mathrm{Sn}-1 \% \mathrm{Nb}-.4 \% \mathrm{Fe}$ samples containing fine particle (a); and aggregates of coarse particles (b)

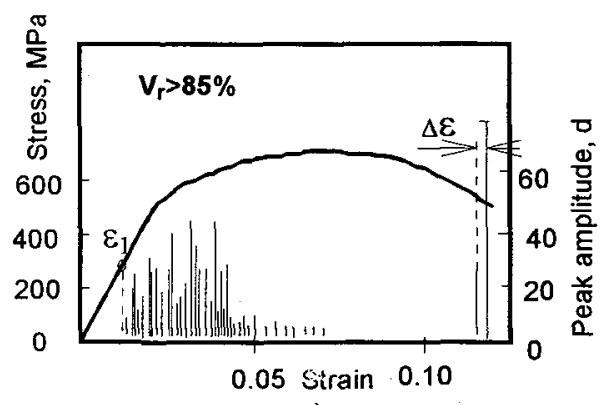

a)

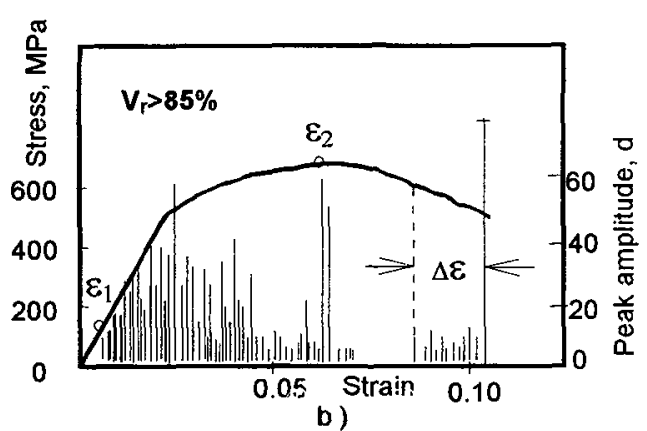

b)

Figure 4: Diagrams of strain and $\mathrm{AE}$ upon tension of hydrogenated $\mathrm{Zr}-2.5 \% \mathrm{Nb}$ samples containing fine (a) and coarse (b) hydrides.

In fine hydride containing specimens even at a low strain (up to $\varepsilon=1.5 \ldots 2 \%$ ) hydrides reveal microcracks [8] but as a rule they do not result in a total loss of flow stability and necking. In this case, too, the neck results from a geometrical loss of strengh.But the hydrides change the fracture formation in the neck: their destruction accompanied by pore formation and coalescence accelerates the evolution of the neck and the fracture of the specimen. Due to this fact the total per cent elongation of fine hydride containing specimens is by $\Delta \varepsilon=5$ $15 \%$ lower than that of hydride free ones.

As distinct from axial fine hydride containing specimens the axial coarse hydride (50-200 $\mu \mathrm{m}$ long) containing ones at uniform strain give rare signals of high amplitude (3-50 dB) (fig. 4) and a neck results at $\varepsilon_{u}<n$ (fig. 5c). Here other mechanism and kinetics of tough fracture are realized. In this case upon elastic strain in individual hydrides oriented normally to the axis of stresses cracks are initiated. The further plastic strain of the matrix results in the reorientation of destroyed hydrides along the specimen axis, namely, in the uniformly strained area axial stringers of hydrides $0.3-1 \mathrm{~mm}$ long are observed, while in the specimen heads the hydrides retain their initial orientation. For the reorientation to take place preliminary multiple breaks of non-axially oriented hydrides are needed which together with the destruction of groups of hydrides crossing the lines of slipping and twinning results in $\mathrm{AE}$ of a large amplitude (30-50 dB) against the background af a diminishing (also in the amplitude) single cracking of hydrides (fig. 4). Hydride cracking leads to an early loss of flow stability upon tension at $\varepsilon_{\mathrm{u}}<\mathrm{n}$. 
Thus, depending on the differences in the strengthening mode and the structure features of $\mathrm{Zr}$-alloys two alternative routes of flow stability loss are realized, namely, due to either " $\mathrm{a}$ geometrical loss of strength" or "internal necking"- cracks. Differences in the deformability and versions of flow stability losses are unumbiguously revealed by joint measurements of tensile diagrams and AE.

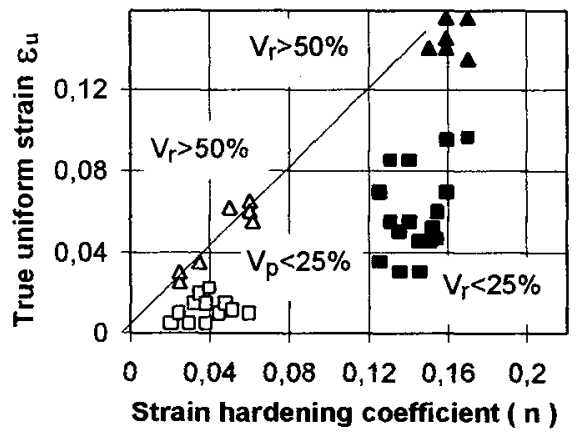

a)

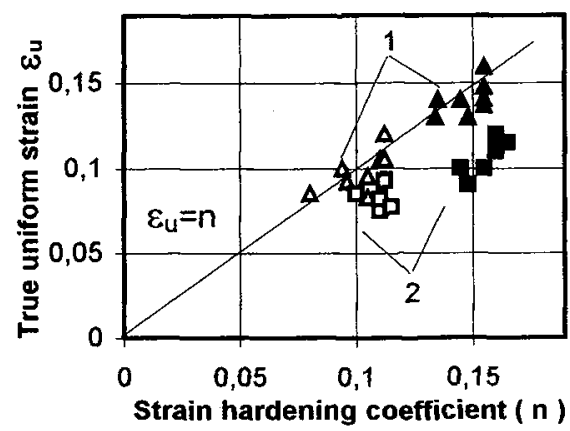

b)

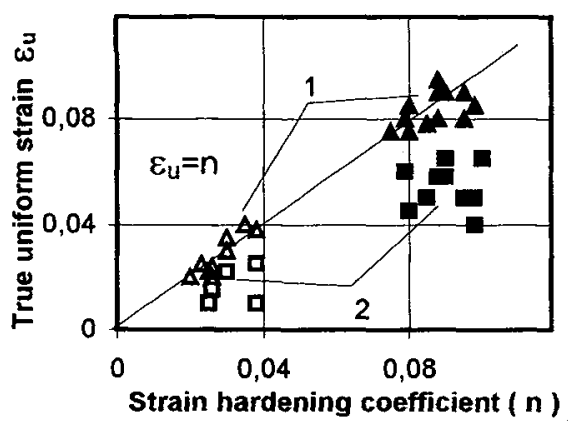

c)

Figure 5: Ratio between anticipated $\left(\varepsilon_{\mathrm{u}}=\mathrm{n}\right)$ and observed uniform tensile strain of $\mathrm{Zr}$-alloy samples: (a) $\mathrm{Zr}$ $2.5 \mathrm{Nb}$ alloy; (b) $\mathrm{Zr}-1.3 \mathrm{Sn}-1 \mathrm{Nb}-0.4 \mathrm{Fe}$ alloy containing fine particles $(\Delta, \Delta)$ and coarse particle aggregates $(\square, \boldsymbol{\square})$;

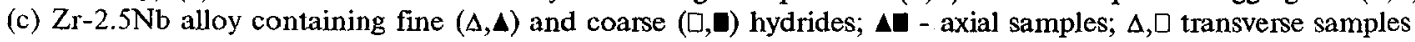

\subsection{Mechanism of Secondary Phase Particle Influence}

As distinct from $\mathrm{Zr}-2.5 \mathrm{Nb}$ alloy, the important structural factor that governs the ductility level and fracture resistance of $\mathrm{Zr}-1.3 \mathrm{Sn}-1 \mathrm{Nb}-0.4 \mathrm{Fe}$ alloy is intermetallic phase particles.

For the detailed studies of the influence produced by particles on the ductility and tough fracture the alloy conditions were chosen having different structures of matrices (polygonized, partially or fully recrystallized) and different secondary phase particle distribution within matrices (uniform distribution of fine particles, with their stringers or with coarse particle aggregates). 

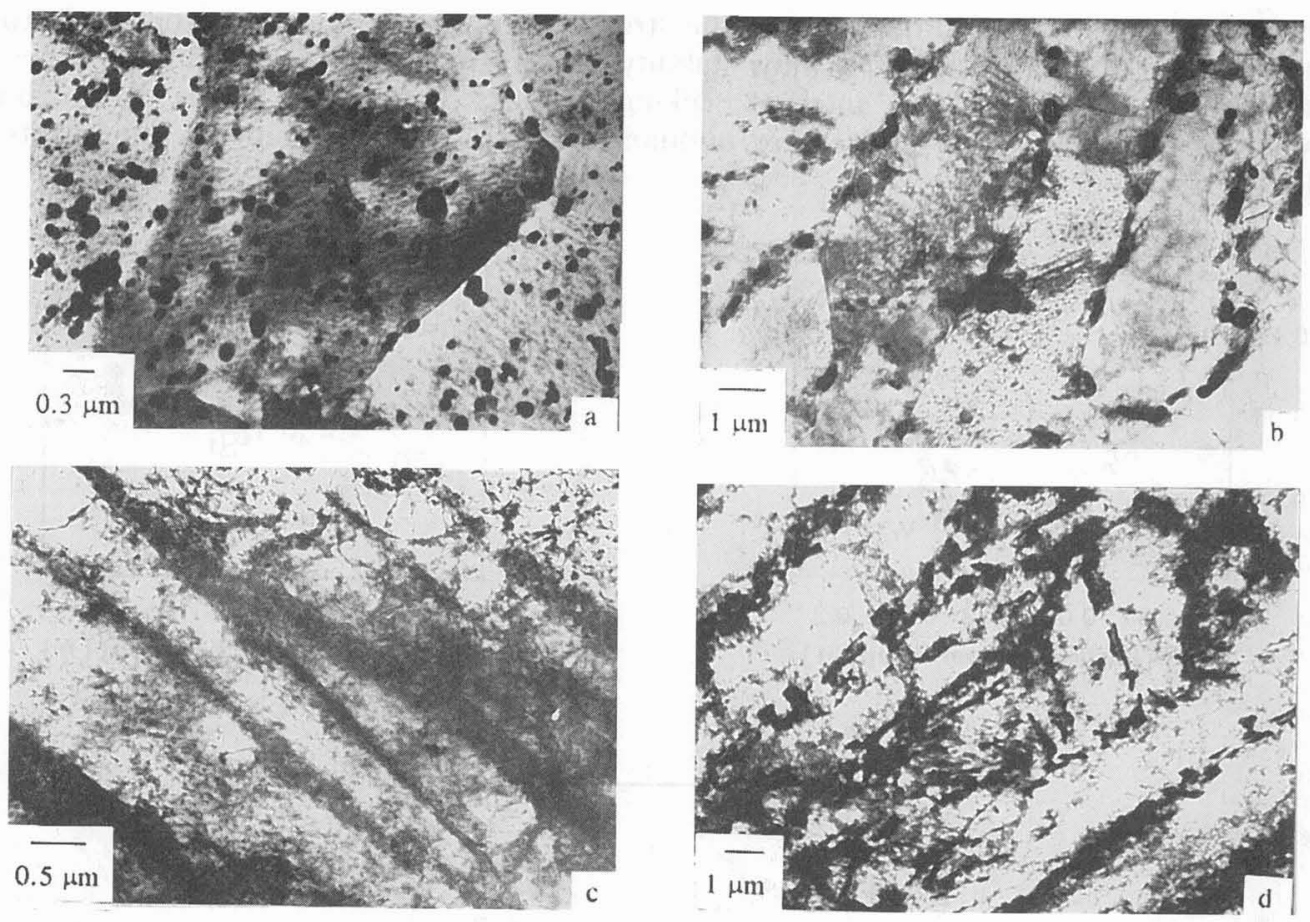

Figure 6: Microstructure of $\mathrm{Zr}-1.3 \mathrm{Sn}-1 \mathrm{Nb}-0.4 \mathrm{Fe}$ alloy in states studied: a) particles uniformly distributed within the recrystallized $\alpha$-matrix grains; b) recrystallized $\alpha$-matrix with stringes of fine particles or with coarse particle aggregetes; c) polygonized $\alpha$-matrix within interlayers of eutectoid; d) polygonized $\alpha$-matrix with particle stringers.

The alloy as annealed after quenching from $950^{\circ} \mathrm{C}$ from the $\beta$-region shows the highest ductility and toughness if the $\alpha_{\mathrm{Zr}}$-matrix structure is uniform polygonized (fragmented) with thin interlayers of fine-grained eutectoid (without intermetallic particle precipitation) which is provided by anneal at $450-500^{\circ} \mathrm{C}$. Particle stringers as precipitated in place of $\beta$ Zr -phase interlayers with the anneal temperature increased to $600-650^{\circ} \mathrm{C}$ lead to lower ductility and toughness.

The particle stringers that appear after anneal noticeably reduce the uniform strain almost without changing the strengthening coefficient $\mathrm{n}$. For all the specimens having particle stringers $\varepsilon_{\mathrm{u}}<\mathrm{n}$. Upon tension of those specimens at the uniform strain stage strong AE signals are recorded having the amplitudes of $15-25 \mathrm{~dB}$ after this the necking in specimens results. For all the specimens without particle stringers (as annealed at $450-500^{\circ} \mathrm{C}$ ) the relation $\varepsilon_{\mathrm{u}}=\mathrm{n}$ is fulfilled and upon tension no strong $\mathrm{AE}$ signals are recorded until the specimen is completely fractured. The tensile specimens without particle stringers have a tough cup-like fracture of a relatively uniform dimple structure at the bottom. At the bottom of dished fractures in specimens having particle stringers against the background of a tough low dimple fracture there are secondary cracks and facets of a quasicleavage type at the sites of elongated stringers of secondary phase particles. 
With a tough crack evolution the particle stringers while localizing the strain give rise to a quasicleavage even in a relatively tough and ductile polygonized matrix. This results in a drop of impact toughness and crack resistance.

An increased uniformity of secondary phase precipitates at the expense of elimination of elongated particle stringers with the simultaneous matrix recrystallization significantly increases the alloy toughness. However, even though the matrix is almost fully recrystallized $\left(\mathrm{V}_{\mathrm{r}}>85 \%\right)$ in this case too aggregates of coarse particles (up to 1.0-1.2 $\mu \mathrm{m}$ in size) can be a cause of a significant reduction in uniform ductility and fracture resistance. By varying the iron content of the alloy within $0.2-0.46 \%$ and the WHT conditions different structures were attained either with the uniform distribution of finely dispersed secondary phase particles (in alloys containing $0.2-0.33 \% \mathrm{Fe}$, the WHT schema with quenching) or with a significant amount of coarse intermetallic particles that are grouped near the grain boundaries (in alloys containing $0.36-0.46 \% \mathrm{Fe}$, the WHT schema without quenching).

The loss of the flow stability under tension due to cracks formed on coarse particle aggregates results not only in lower uniform ductility but is also accompanied by a decrease in the energy intensity of deformation and fracture of a specimen.
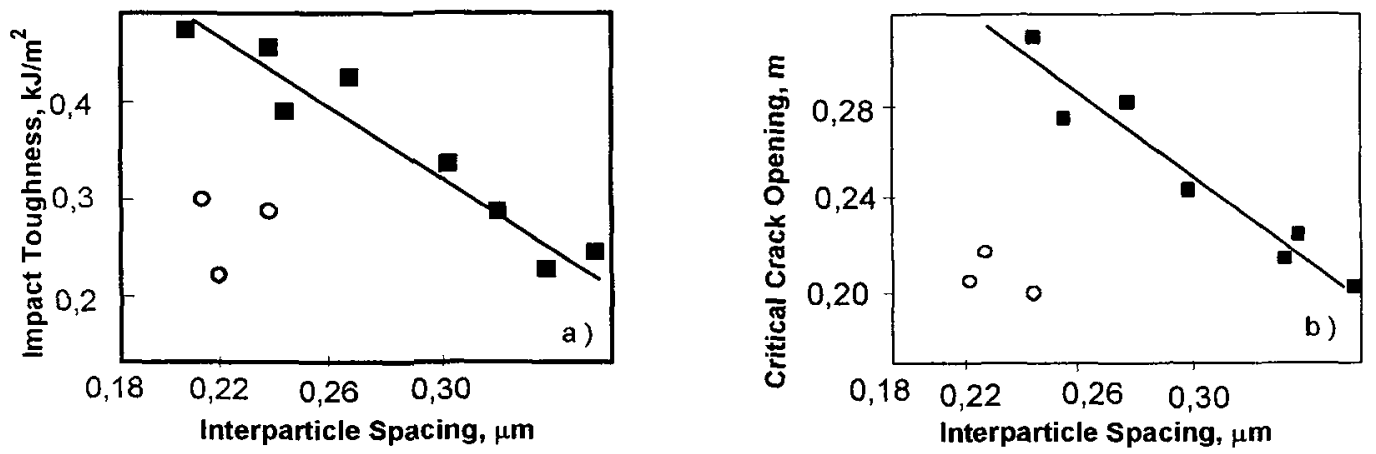

Figure 7: Impact toughness CCV (a) and critical crack opening $\delta_{\mathrm{c}}$ (b) VS interparticle distance in $\mathrm{Zr}$-1.3Sn$1 \mathrm{Nb}-0.4 \mathrm{Fe}$ type alloy with $\mathrm{-}$ - uniform distribution of fine particles and $\mathrm{o}-$ coarse paticle aggregates.

The pore formation upon a tough fracture is primarily controlled by fine (up to $0.2 \mu \mathrm{m}$ ) particles. The further growth and coalescence of pores are dictated by the matrix ability for deformation (the strengthening coefficient $n$ ) and the interparticle distance. Taking into account that all the alloys have a close strengthening coefficient $n=0.12-0.15$ the stage of the pore coalescence is governed by the interparticle distance. Fig. 7 shows the dependences of the impact toughness and critical crack opening $\left(\delta_{c}\right)$ upon the interparticle distance $(\lambda)$ and particle distribution density $(\rho)$ for all alloys of $\mathrm{Zr}-1.2-\mathrm{Sn}-1 \mathrm{Nb}-0.4 \mathrm{Fe}$ type and all treatments. It can be seen from the figure that the impact toughness and critical crack opening linearly increase with an interparticle distance decrease (or with a particle density increase).

From the general dependences only points fall out that correspond to the conditions having coarse particle aggregates that reduce much the toughness and crack resisitance of the alloy (fig. 7).

Thus, microcraks (pores) formed on coarse particles or particle aggregates under strain reduce the alloy ability for stable plastic flow and accelerate a tough crack evolution which in its turn results in lower technological ductility and crack resistance. 


\section{CONCLUSION}

The inital distinctions in the mode of material strengthening give rise to two routes of plastic flow stability loss and two chains of tough fracture events:

a) "geometrical" softening-loss of stability at $\varepsilon_{\mathrm{u}}=\mathrm{n}$ - a crack initiation on a neck axis - a long neck (maximum elongation on specimen axis) -plane cup-like surface fracture;

b) a crack initiation (internal neck) at $\varepsilon_{\mathrm{cr}} / \varepsilon_{\mathrm{u}}$ - loss of stability $\varepsilon_{\mathrm{u}}<\mathrm{n}$ - growth and coalescence of pores - a short neck, a deep cup (maximum elongation at the circumference of a cup).

The realization of the route of the flow stability loss depends on both the coefficient of strengthening $n$ (type of the strain diagram) and the structure features at the specified $n$. Since the ultimate uniform strain $\varepsilon_{\mathrm{u}}{ }^{\max }=\mathrm{n}$, and in alloys it is often $\varepsilon_{\mathrm{u}}<\mathrm{n}$ two routes are possible to govern the plastic flow stability, namely, via increasing the coefficient of strain hardening, $n$, and via increasing the critical strain $\varepsilon_{c r}$

The former route of increasing ductility has been realized in two-phase ferritic-martensitic steels and in martensitic-austenitic "duplex" steels $[4,5]$ having high ductility and toughness.

As for $\mathrm{Zr}$-alloys the texture alters the coefficient $n$. With the specified WHT the texture is permanent and the main way of increasing the uniform ductility $\varepsilon_{u}$ is to eliminate the structure relevant causes of the early loss of flow stability at $\varepsilon_{\mathrm{u}}<\mathbf{n}$. In $\mathrm{Zr}-2.5 \mathrm{Nb}$ alloy having the $\alpha_{\mathrm{Zr}^{-}}$-solid solution structure and a small number of fine secondary phase particles (the volume fraction of $1.5-2.0 \%$ ) $0.01-0.1 \mu \mathrm{m}$ in size the uniform strain with the texture specified is mainly determined by the matrix recrystallization grade $V_{\mathrm{r}}$.

Coarse secondary phase particles non-uniformly distributed within a matrix may significantly change the flow stability of $\mathrm{Zr}$-alloys even in the recrystallized condition. For alloys of the $\mathrm{Zr}-1.3 \mathrm{Sn}-1 \mathrm{Nb}-0.4 \mathrm{Fe}$ type containing up to $3-3.5 \%$ vol secondary phase particles the main cause of the flow stability loss is coarse (up to $1 \mu \mathrm{m}$ in size) intermetallic particles non-uniformly distributed within a matrix. In this case $\varepsilon_{\mathrm{u}}$ may be increased through refining intermetallic particles and improving their distribution uniformity, e.g., by WHT with $\beta$ quenching prior to cold rolling operations [9].

The fracture resistance of $\mathrm{Zr}-2.5 \mathrm{Nb}$ alloys may be improved by increasing the total and local ductility through the $\mathrm{Zr}$-matrix recrystallization.

This is insufficient for the alloys of the $\mathrm{Zr}-1.3 \mathrm{Sn}-1 \mathrm{Nb}-0.4 \mathrm{Fe}$ type and the size and density of intermetallic particle precipitation need be regulated. This way of increasing the toughness is only possible at the relatively low volume fraction of secondary phase particles (less than $10 \% \mathrm{vol}$ ) when individual particles behave independently during a fracture evolution by the mechanism related to pore initiation and growth. In the alloys containing a high volume fraction of secondary phase particles $(30-60 \%$ vol) the refinement of particles results in a condition when cooperative effects of the particle influence on the tough crack evolution start acting. In this case a decreased interparticle distance leads to lower toughness.

\section{Acknowledgements}

The authors would like to thank the following people who helped in carring out these experiments: V.G. Khanzhin for acoustic emission measurements, E.Y. Kurianova and A.P. Markelov for overall technical assistance. 


\section{References}

[1] Backofen W.A. "Deformation Processing”, Metallurgia, Moscow, 1977, 288 p.

[2] "Fracture" (An Advanced Treatise) edited by H.Liebowitz, Academic press, New York and London, 1969, vol.6.

[3] Hollomon J.H." Tensile Deformation" Transaction AIME, 1945, vol.162, pp. 268-290.

[4] Shtremel M.A., Nikulin S.A., Kanev V. "Tough Fracture of High Mangnese Steel" Izvestiya AN SSSR, Metals, 1981, №4, pp. 98-106.

[5] Nikulin S.A., Shtremel M.A., Khanghin V.G. "On Tough Fracture of High Manganese Steel under Tension”, Izvestiya AN SSSR, Metals, 1990, № 1, pp.141-151.

[6] Khanghin V.G., Shtremel M.A., Nikulin C.A. "Assessment of Internal Crack Sizes from Peak AE Amplitudes", Defectoskopiya, 1990, № 4, pp.35-40.

[7] Nikulin S.A., Markelov V.A. et al." Influence of Structure on Strain Diagrams of Zr-2.5\% Nb alloy", Izvestiya An SSSR, Metals, 1991, №3, pp.134-139.

[8] Nikulin S.A., Shtremel M.A., Khanzhin V.G., Fateev B.M., Markelov V.A. "Influence of Hydrides on Ductile Fracture in the $\mathrm{Zr}-2.5 \% \mathrm{Nb}$ Alloy", Nuclear Science and Engineering, 1993, vol. 115, pp. 1993-204.

[9] Nikulin S.A., Markelov V.A., Goncharov V.I., Shishov V.N.

"Effects of Microstructure on Ductility and Fracture Resistance of $\mathrm{Zr}-1.3 \mathrm{Sn}-1 \mathrm{Nb}-0.4 \mathrm{Fe}$ Alloy", Eleventh International Symposium on $\mathrm{Zr}$ in the Nuclear Industry, Garmish, Germany, 1995, ASTM STP 1295, 1996, pp. 99-112. 